\title{
DESIGN PROTOTYPE E-SERVICE UNTUK MENINGKATKAN PELAYANAN BISNIS UMKM PADA JENIS USAHA JASA LAUNDRY
}

\author{
Ri Sabti Septarini', Syepry Maulana Husain ${ }^{2}$ \\ 1,2 Program Studi Informatika, Fakultas Teknik \\ Universitas Muhammadiyah Tangerang \\ risabtis@gmail.com ${ }^{1}$, syepry.maulana@ft-umt.ac.id ${ }^{2}$
}

\begin{abstract}
ABSTRAK
Dalam dunia bisnis, dampak postif teknologi kini tidak hanya bisa dirasakan oleh bisnis skala besar. Usaha Mikro Kecil dan Menengah (UMKM) yang dijalankan dengan melibatkan teknologi informasi dan komunikasi dalam hal ini akan membuat usaha menjadi lebih mudah, lebih cepat dan lebih dapat diandalkan. Contohnya Jasa laundry banyak sekali ditemui terutama di daerah-daerah sekitar kampus atau pabrik. Jasa laundry yang ditawarkan juga sangat beragam, ada yang menggunakan sistem paket atau menggunakan jasa antar jemput cucian. Masalah yang sering dialami costumer adalah keterbatasan waktu mereka dalam melakukan laundry, segala sesuatu yang ingin instan dan cepat dalam proses laundry, dengan kecanggihan teknologi informasi dan komunikasi yang ada saat ini dengan dijembataninya internet, jika dimanfaatkan secara maksimal dapat meningkatkan nilai liberty laundry pada bisnis online, memudahkan aktivitas costumer dan memberikan kepuasaan costumer dengan bantuan media aplikasi web e-service laundry.
\end{abstract}

Kata Kunci: UMKM, Customer, Teknologi Informasi, Aplikasi Web, Laundry.

\begin{abstract}
In the business world, both the big and small scale business feel the positive impacts of technology. UMKM activities involving the information and communication technology are easier, faster, and more dependable. For example, we can find any laundry services especially around campuses or factories. The laundry services give various packages such as a package system, pick-up service and delivery service. The most common problem had by the customers is that they have very limited time to take their laundry to the laundry service. What they need is a quick and instant services. With the advancement of information and communication technology connected with sophisticated internet, people who provide laundry services can make a good use of "liberty laundry" for their online business so that they can help the customers with their laundry and give them a satisfying service through a web-based - e-service laundry.
\end{abstract}

Keywords: UMKM, Customer, Teknologi Informasi, Aplikasi Web, Laundry.

\section{PENDAHULUAN}

Dalam perkembangan e-service telah menggantikan model pelayan yang bersifat tradisional dan juga self service. Ada beberapa perbedaan utama antara tradisional dan $e$ service. Dalam e-service, karyawan yang terlibat dalam antarmuka dimediasi oleh internet. Selain itu, selama pertemuan $e$ service, pelanggan dibatasi untuk mendengar dan melihat [6].

Kepuasaan pelanggan adalah suatu hal yang penting bagi perusahaan dapat meningkatkan kualitas pelayanan yang memberikan dampak positif agar usaha dapat berjalan, hubungan antar pelangganpun harus tetap dijaga dengan meberikan pelayanan yang terbaik dalam bisnis jasa. Laundry merupakan suatu bagian untuk memproses semua aktivitas pencucian baik bersifat menggunakan air ataupun uap(dry cleaning). Begitu banyak jasa laundry pada saat ini dalam UMKM baik pada wiayah lingkungan perkantoran, perumahan, universitas, akan tetapi pemanfaatkan dengan media teknologi belum sepenuhnya digunakan dalam pengelolaan bisnis.

Berdasarkan penjelasan diatas ditemukan beberapa masalah yang diidentifikasikan sebagai berikut : 
1. Laundry belum menggunakan teknologi informasi dalam proses pemesanan laundry costumer.

2. Keterbatasan waktu costumer menjadi kendala pada saat costumer ingin melakukan laundry.

3. Costumer yang ingin instan dan cepat dalam proses laundry.

Permasalahan yang dihadapi UMKM dalam merencanakan pengembangan sistem informasi.

1. Bagaimana cara mengatasi permasalahan costumer yang memiliki keterbatasan waktu untuk datang langsung ketempat laundry?

2. Bagaimana cara meningkatkan bisnis online pada liberty laundry?

3. Bagaimana cara memenuhi keinginan costumer yang ingin cepat dalam melakukan pemesanan laundry?

Batasan masalah yang dilakukan hanya membahas bagaimana cara mengatasi permasalahan costumer pada kasus liberty laundry (UMKM) yang memiliki keterbatasan waktu, ingin cepat dan efisien dalam melakukan pemesanan laundry.

\section{TINJAUAN PUSTAKA}

Penelitian ini bertujuan untuk UMKM menambah manfaat dalam menawarkan jasa terhadap pelanggannya dalam memberikan kepuasan dan kenyamanan agar tujuan mereka tercapai demi mempertahankan bisnis.

Beberapa hal penulisan yang terkait dalam penelitian E-Service berdasarkan referensi jurnal dan buku. Dalam E-Service juga pelanggan dengan mudah dapat menerima layanan melalui internet dirumah atau tempat lain. Pengertian dari e-service sebagai penyediaan layanan melalui jaringan elektronik seperti internet. Selain itu, e-service sebagai kujungan awal dari homepage sampai layanan yang diminta atau produk akhir telah disampaikan dan layak digunakan[3].

Kualitas pelayanan dapat berhubungan dengan potensi layanan (misalnya, kualifikasi pekerja); proses pelayanan (misalnya, kecepatan pelayanan) dan hasil dari layanan yaitu kepuasan pelanggan. Kualitas layanan individu merupakan gambaran nyata kualitas layanan seorang karyawan dari kualitas yang dirasakan pelanggan[8].

Kualitas layanan elektronik sebagai berikut :
1. Kualitas layanan elektronik "sejauh mana sebuah situs web memfasilitasi efisien dan efektif belanja, pembelian, dan pengiriman."[7]

2. Kualitas layanan elektronik "awal hingga akhir transaksi, termasuk pencarian informasi, navigasi website, pesanan, interaksi layanan pelanggan, pengiriman, dan kepuasan dengan produk yang dipesan.[9]

Pemanfaatan website e-service merupakan salah satu penunjang keberhasilan bisnis dalam memberikan pelayanan elektronik yang memberikan kemudahan dalam transaksi.

\section{METODOLOGI}

Pembahasan ini mengambil contoh kasus salah satu usaha UMKM laundry ini dinamakan CV. Liberty. Nama liberty itu sendiri mengandung arti Life simple, Is professional, Bermutu \& bersaing, Easy, fresh, higienic \& clean, Ramah \& Rajin, Terpercaya, terbaik untuk kepuasan costumer. Dalam pengumpulan data maupun informasi yang diperlukan untuk mendapatkan kebenaran materi uraian pembahasan, dengan metode pengumpulan data yang terdiri dari :

\section{A. Metode Wawancara}

Metode ini dilakukan dengan cara mewawancarai pemilik, memberikan permasalahan yang dihadapi costumer liberty laundry, sehingga dapat meningkatkan kepuasan dan memudahkan dalam hal pelayanan aktivitas pelanggan dengan bantuan sistem aplikasi yang akan diusulkan berupa $E$ Service Liberty Laundry.

\section{B. Metode Observasi}

Mengamati langsung bagaimana aktivitas proses pelayanan yang ada pada Liberty Laundry agar data laporan yang didapat lebih lengkap dan akurat.

\section{Metode Studi Pustaka}

Dalam melakukan studi pustaka penulis melengkapi kekurangan-kekurangan data yang diperoleh dari studi lapangan. Pengumpulan data dengan cara mengambil dari sumbersumber media cetak maupun elektronik yang dapat dijadikan acuan pembahasan masalah.

\section{Metode Pengembangan Sistem}


Pembahasan menggunakan model Sekuel Linier. Model ini juga disebut dengan 'siklus kehidupan klasik' atau 'model waterfall', dimana sekuel linier mengusulkan sebuah pendekatan pengembangan perangkat lunak yang sistematik.

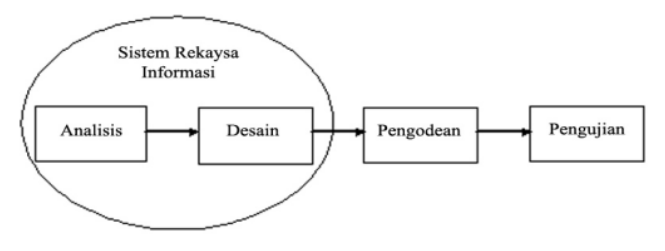

Gambar 1. Pengembangan Sistem Model Waterfall

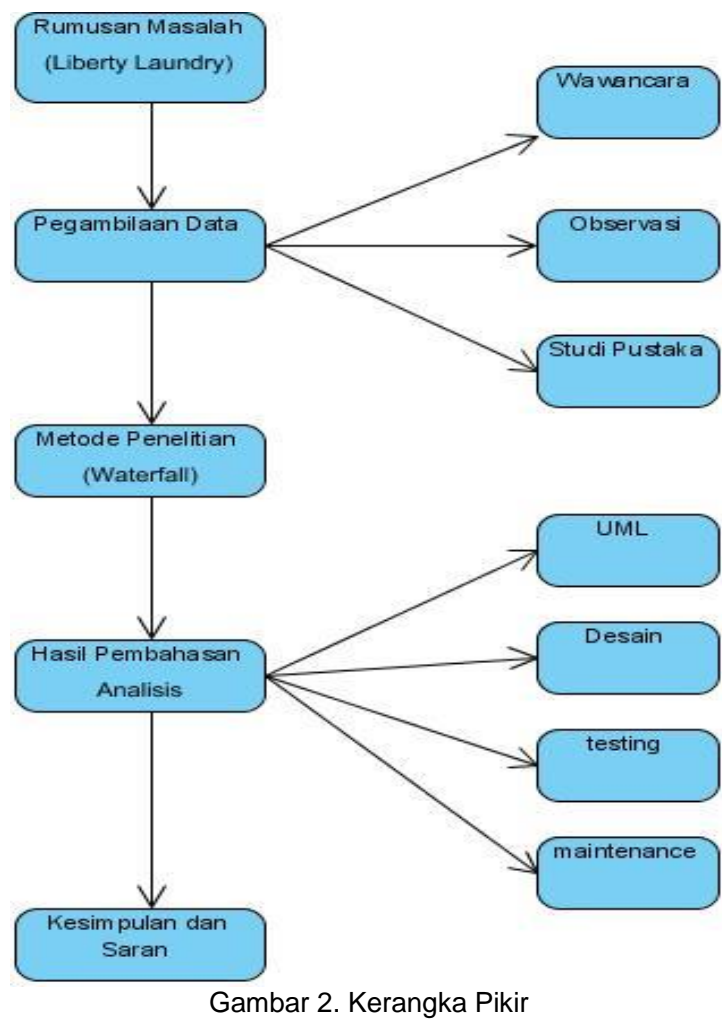

Tahap Rekayasa Sistem dan Perencanaan

\section{a. Analisis}

Pada proses analisis, teknik analisis yang dilakukan adalah :

1. Analisis data dan informasi sistem yang berjalan. Analisis dilakukan terhadap prosedur, dokumen, file dan hasil cetakan dari sistem sistem yang sudah berjalan.

2. Analisis kebutuhan fungsional, nonfungsional dan pengguna. Pemodelan kebutuhan fungsional untuk menggambarkan fungsi sistem dan pengguna yang terlibat serta fungsi-fungsi apa saja yang bisa didapatkan oleh masingmasing pengguna dimodelkan dengan Use case diagram.

3. Analisis perilaku sistem. Pada tahapan ini, dilakukan analisis perilaku sistem yang dikembangkan dan dimodelkan dengan statechart diagram, activity diagram dan sequence diagram. Statechart diagram dan activity diagram untuk memodelkan proses use case diagram yang berjalan didalam sistem didalam sistem. Sedangkan sequence diagram memodelkan pengiriman pesan (message) antar object dan kronologi.

\section{b. Desain}

Dalam perancangan sistem aplikasi e-service liberty laundry ada beberapa usulan dari pihak liberty laundry.

1. Bentuk perancangan sistem memudahkan akses costumer dalam mengetahui tata letak form / interface (antar muka) berupa warna, tulisan, gambar dan icon.

2. Tampilan sistem aplikasi harus dapat menyesuaikan (Responsive) penggunaan dalam bentuk media, komputer dan gadget.

3. Perancangan database disesuaikan dengan kebutuhan yang akan diusulkan untuk membuat sistem aplikasi e-service liberty laundry.

\section{c. Coding}

Dalam perancangan sistem aplikasi e-service liberty laundry menggunakan :

1. Bahasa pemograman: PHP

2. Database : MySQL

3. Design : Adobe Dreamweaver

\section{d. Testing}

Pengujian sistem dilaksanakan berupa dokumen black box. Dalam tahapan pengujian langsung dilakukan oleh pimpinan liberty laundry.

\section{e. Maintenance}

Maintenance untuk sistem aplikasi setelah proses pengujian / testing berhasil dan telah disetujui pihak pimpinan liberty laundry. Untuk tahapan maintenance mengenai bagaimana perawatan sistem aplikasi ang sudah dijalankan.

\section{HASIL DAN PEMBAHASAN}

\section{Tahap Rekayasa Sistem dan Perencanaan}

Perancangan sistem informasi $E$ Service berbasis web pada Liberty Laundry ini dimaksudkan untuk memudahkan costumer dalam melakukan pemesanan laundry dan 
pengiriman laundry, mengatasi permasalahan costumer dan meningkatkan bisnis online pada liberty laundry.

Adapun kelebihan dalam perancangan sistem informasi yang diusulkan ini adalah :

1. Sistem ini menggunakan sistem yang berbasis web sehingga pengguna dapat dengan mudah menggunakan dan mengaksesnya.

2. Dapat meningkatkan bisnis online pada liberty laundry.

3. Dapat memudahkan costumer dalam melakukan pemesanan laundry online sehingga lebih instan dan cepat.

\section{Analisis Sistem Berjalan}

Bertujuan menganalisis sistem yang sedang berjalan sebelumnya dan mengidentifikasikan masalah-masalah yang ada.

Bagan alur dibawah ini menjelaskan proses bagaimanan penerapan pelayanan yang sedang berjalan.

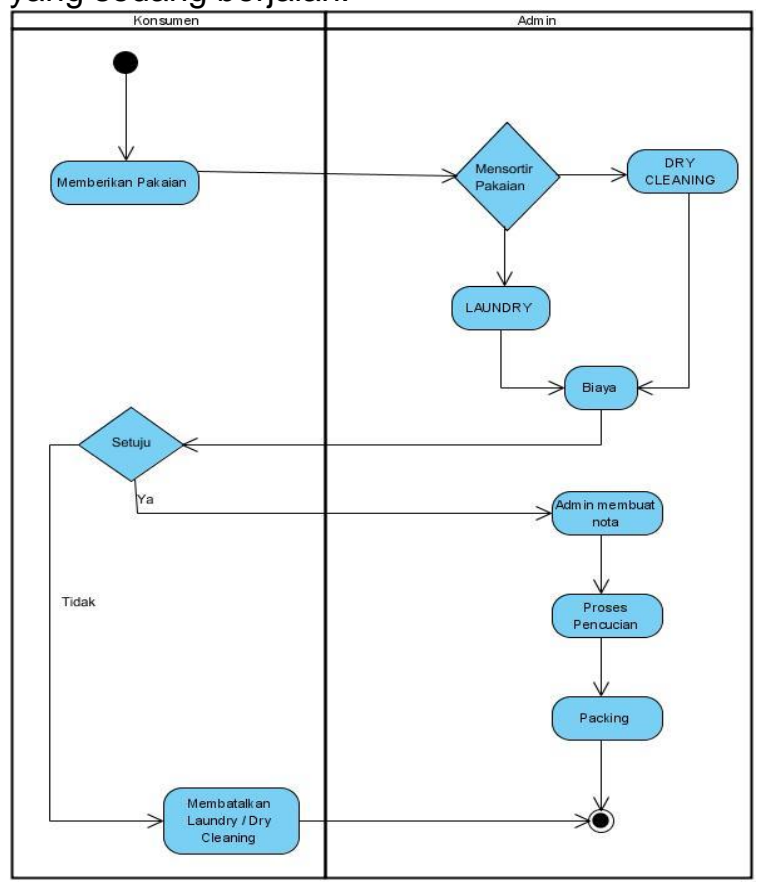

Gambar 3. Alur Proses Pelayanan

\section{Perancangan Use Case Diagram}

Use case Diagram digunakan untuk menjelaskan apa yang dilakukan oleh sistem tersebut serta aktor - aktor yang berhubungan dengan proses-proses yang ada disistem yang diusulkan. Diagram ini melihatkan pada kita hubungan yang terjadi antara aktor-aktor dengan use case-use case dalam sistem.

\section{Use Case Diagram Customer}

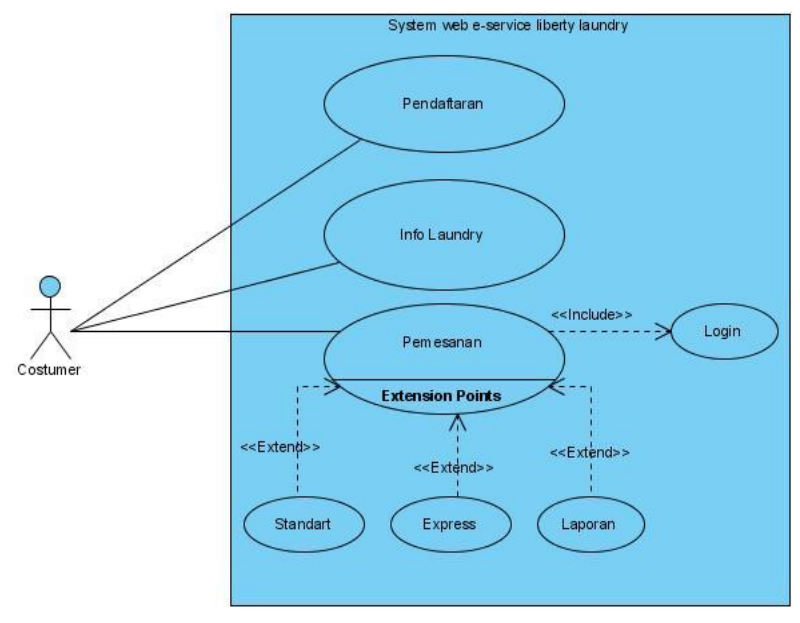

Gambar 4 Use Case Diagram Customer

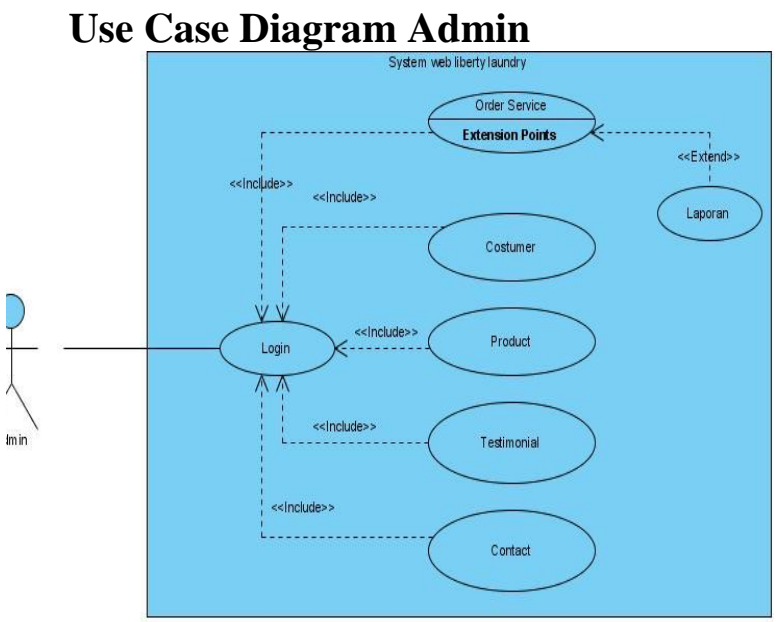

Gambar 5 Use Case Diagram Admin

Perancangan Activity Diagram

Aktivitas Activity Diagram adalah suatu gambaran tentang sistem yang telah dibuat didalam model proses bisnis.

\section{Diagram Activity Login}

Adapun diagram activity login yang diusulkan adalah sebagai berikut : 


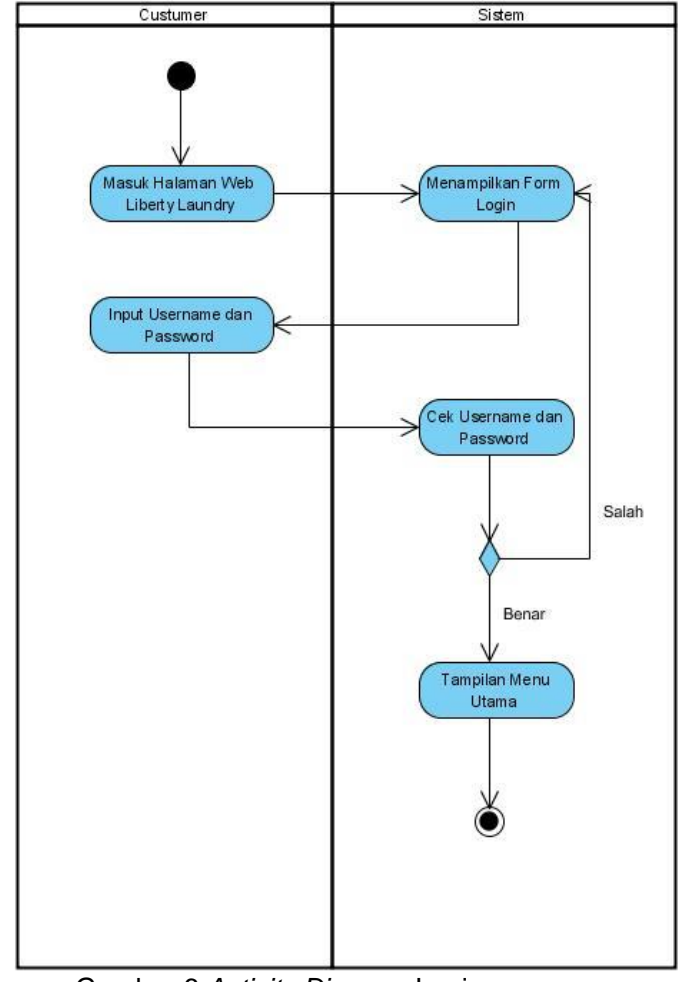

Gambar 6 Activity Diagram Login

\section{Activity Diagram Pendaftaran}

Adapun diagram activity pendaftaran yang diusulkan adalah sebagai berikut :

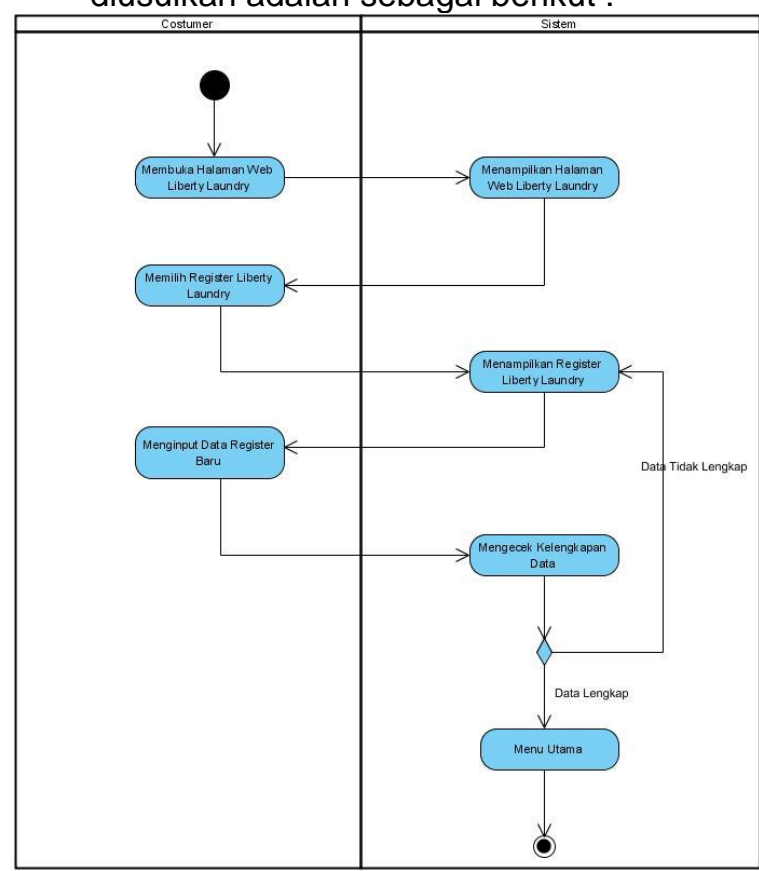

Gambar 7 Activity Diagram Pendaftaran
Activity Diagram Pemesanan

Adapun diagram activity pemesanan yang diusulkan adalah sebagai berikut :

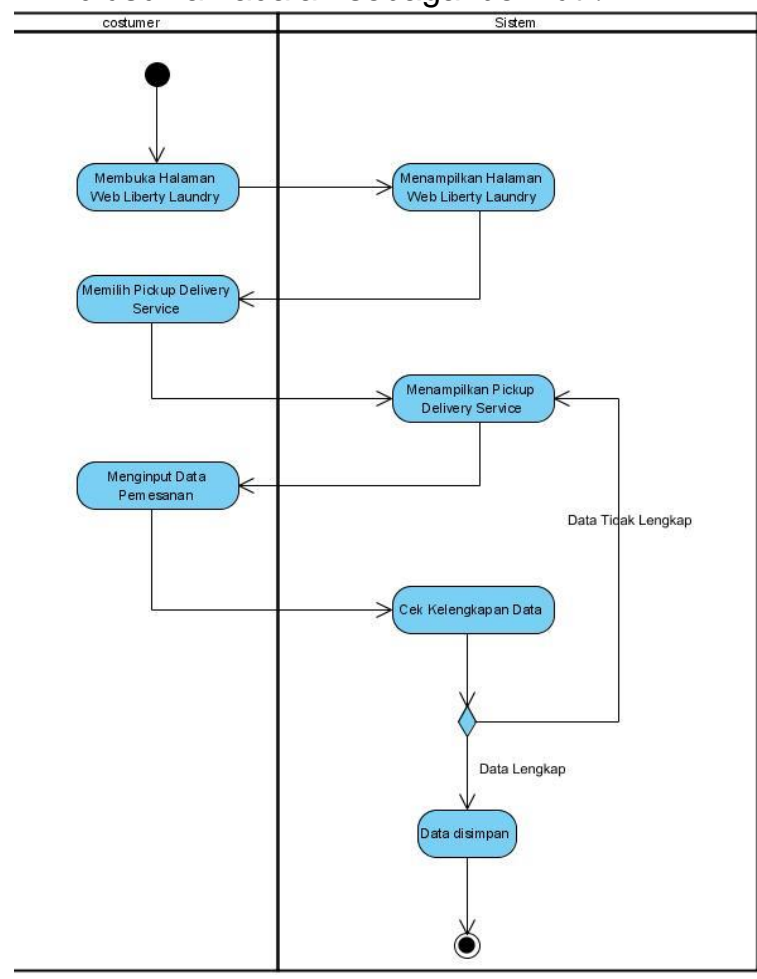

Gambar 8 Activity Diagram Pemesanan

\section{Activity Diagram Admin}

Adapun diagram activity buat surat yang diusulkan adalah sebagai berikut :

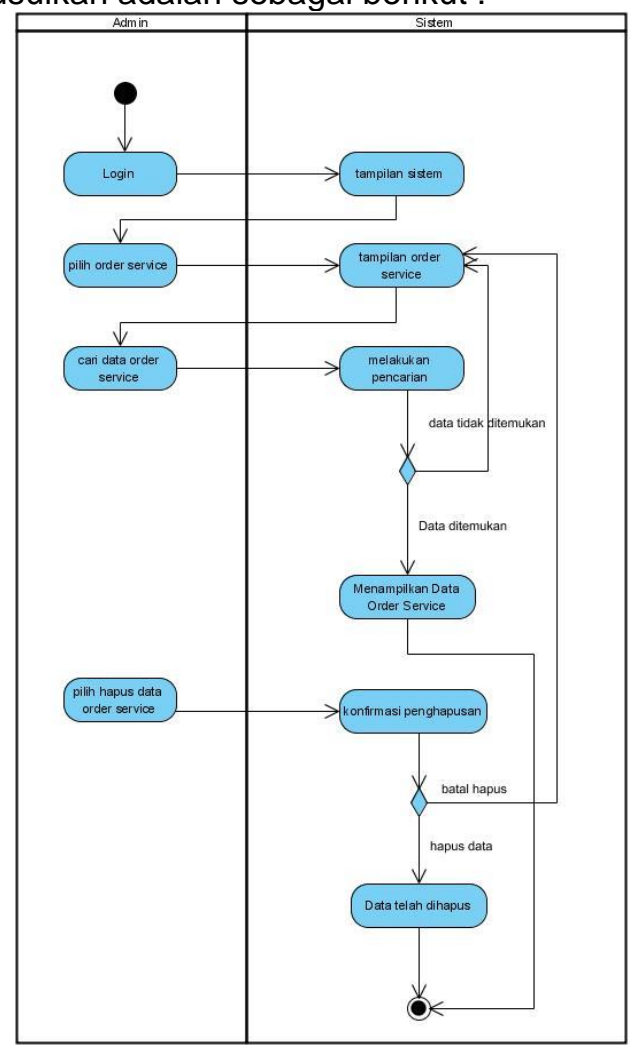


Gambar 9 Activity Diagram Admin

\section{Perancangan Diagram Sequence}

Adi Nugroho (2005:92) sequence diagram adalah interaction diagram yang memperlihatkan event-event yang berurutan sepanjang berjalannya waktu. Masing-masing sequence diagram akan menggambarkan aliran-aliran pada suatu use case.Sequence diagram admin dalam sistem informasi dapat dilihat sebagai berikut:

Sequence Diagram login

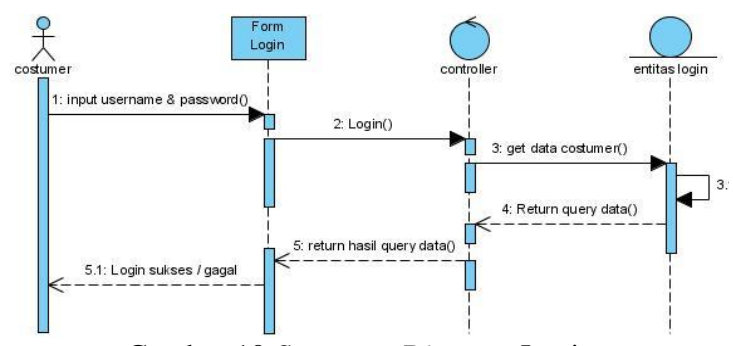

Gambar 10 Sequence Diagram Login

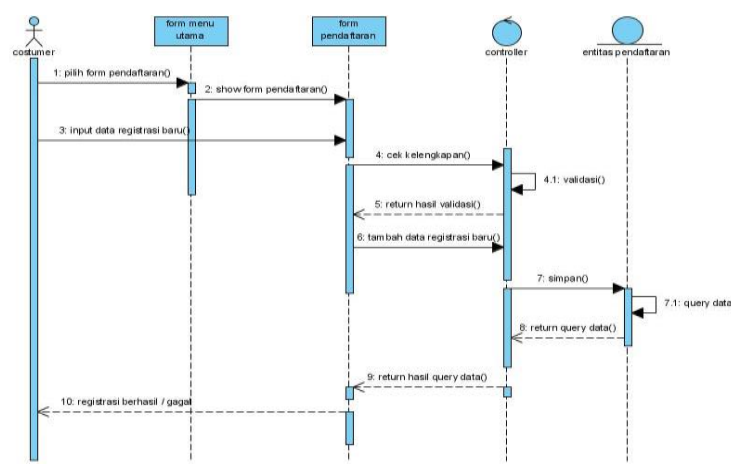

Gambar 11 Sequence Diagram Pendaftaran

\section{IMPLEMENTSI ANTAR MUKA}

\section{Menu}

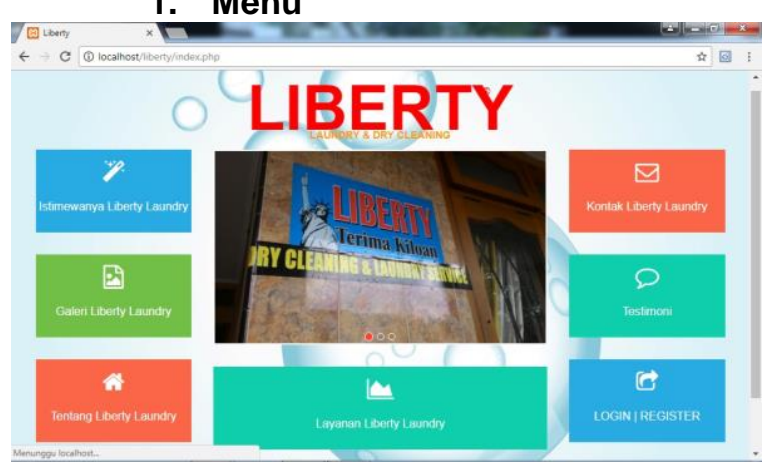

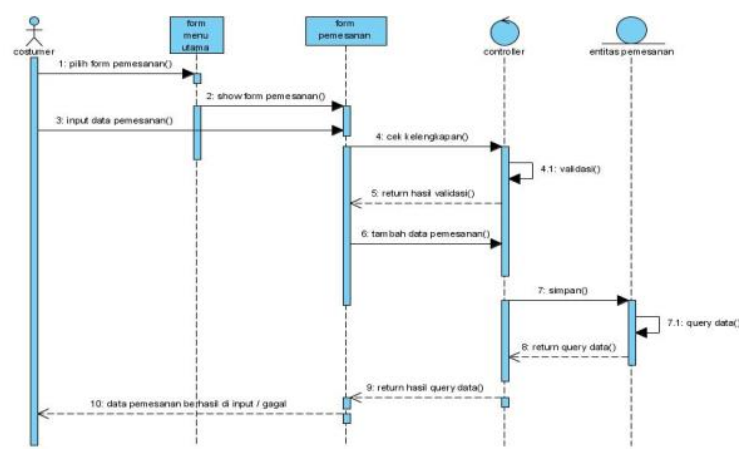

Gambar 12 Sequence Diagram Pemesanan

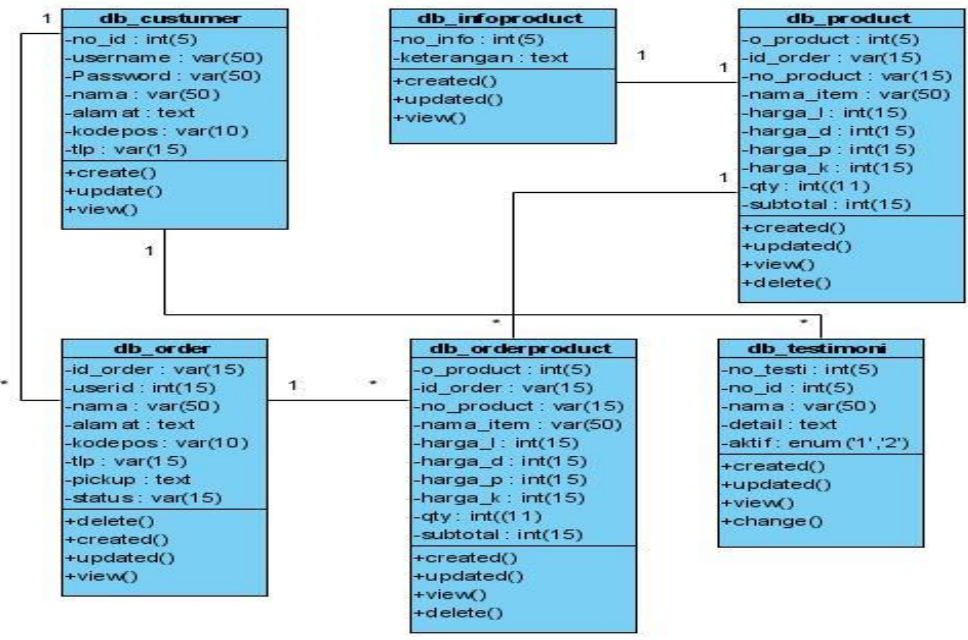

Gambar 14 Class Diagram (Diagram Kelas)

\section{Diagram Kelas (Class Diagram)}

Diagram kelas (class diagram) adalah diagaram yang digunakan untuk menampilkan beberapa kelas yang ada dalam sistem/perangkat lunak yang sedang dikembangkan. Diagram kelas memberikan gambaran tentang sistem/perangkat lunak dan relasi-relasi yang ada. Adapun diagram kelas tahap perencangan

Gambar 15. Form Menu

\section{Menu Profile}

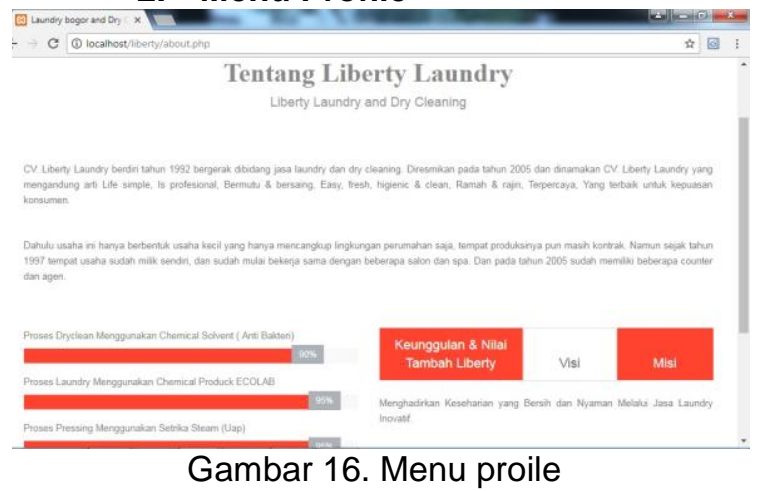

JIKA | 6 


\section{Galeri}

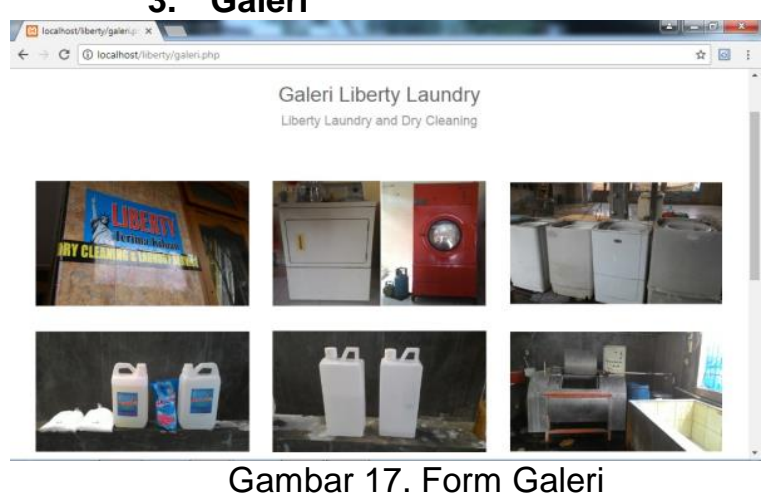

\section{Menu Info Layanan}

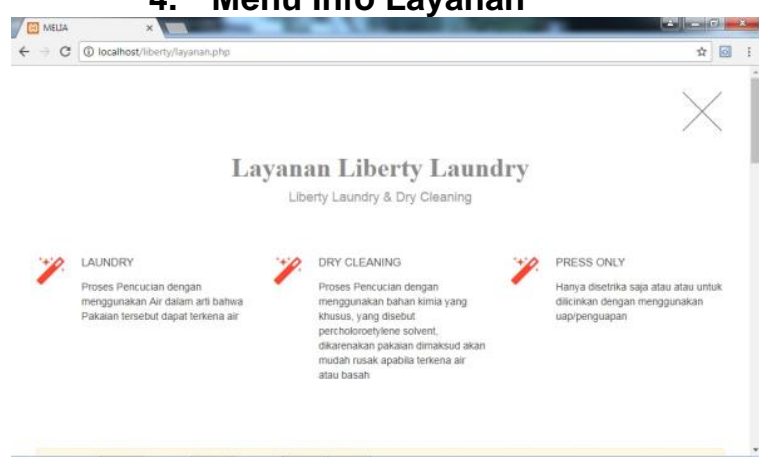

Gambar 18. Menu info pelayanan

Menu Kontak

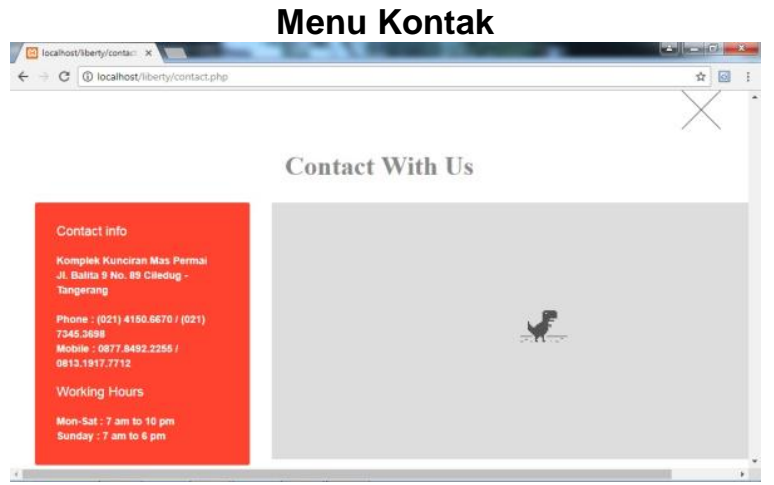

Gambar 19 Menu Kontak

5. Menu Login dan pendaftaran

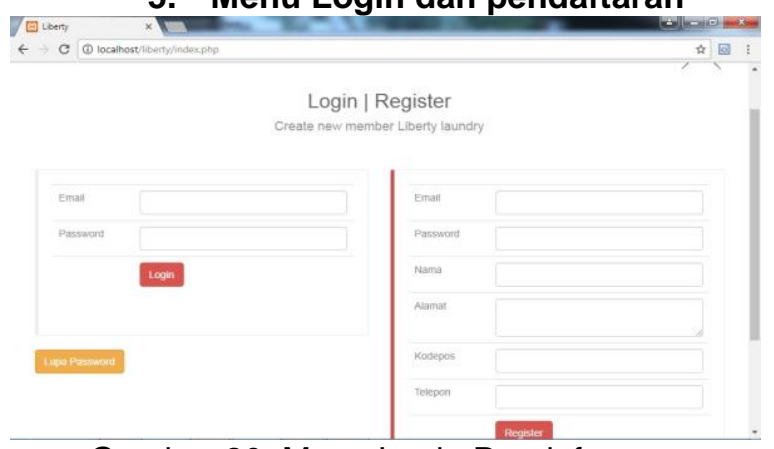

Gambar 20. Menu Login Pendaftaraan

\section{Menu Login Admin}

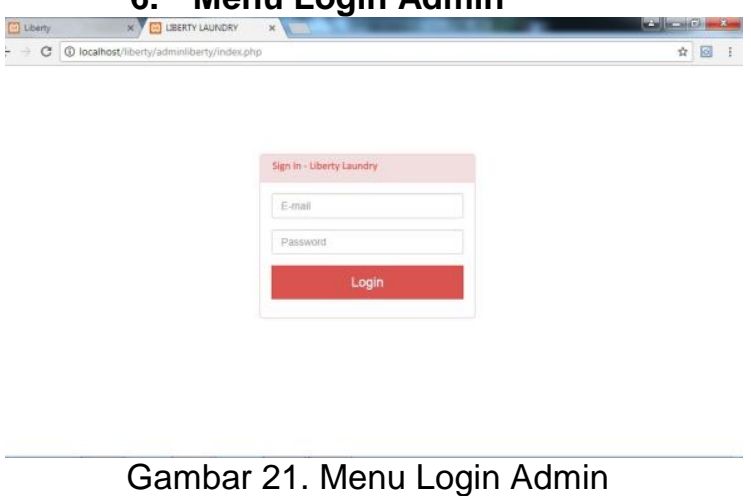

\section{Menu Admin}

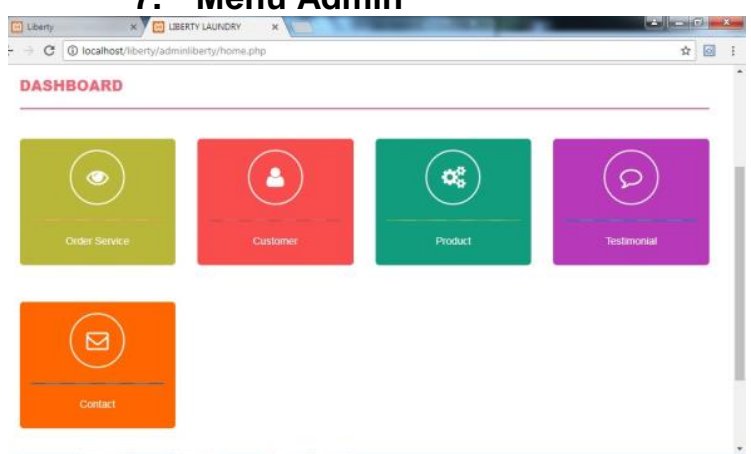

\section{Testing}

Gambar 22. Menu Admin

Setiap program menjalani pengujian untuk memastikan bahwa program yang di bangun bebas dari kesalahan (bug), walaupun tidak menutup kemungkinan masih terjadi sedikit bug atau tidak $100 \%$ bebas dari bug, namun pengujian ini setidaknya bisa meninimalisir kesalahan yang terjadi.

Pengujian dilakukan menggunakan black box, yaitu suatu pendekatan untuk menguji apakah setiap fungsi di dalam program dapat berjalan dengan benar. Berikut ini tabel hasil pengujian dari aplikasi sistem sistem informasi e-service laundry.

\begin{tabular}{|c|c|c|}
\hline $\begin{array}{l}\text { Nama } \\
\text { Testing }\end{array}$ & Keterangan & Status \\
\hline \multirow[t]{2}{*}{ Login } & $\begin{array}{l}\text { 1. Harus memasukkan username } \\
\text { dan password, username dan } \\
\text { password tidak boleh kosong. }\end{array}$ & Ok \\
\hline & $\begin{array}{l}\text { Username dan password } \\
\text { dilakukan pengecekkan melalui } \\
\text { database liberty laundry. }\end{array}$ & Ok \\
\hline \multirow[t]{2}{*}{$\begin{array}{l}\text { View info } \\
\text { laundry }\end{array}$} & $\begin{array}{l}\text { User masuk kehalaman web } \\
\text { liberty laundry }\end{array}$ & Ok \\
\hline & $\begin{array}{l}\text { 2. User memilih info liberty } \\
\quad \text { laundry : } \\
\text { a. Istimewanya liberty laundry } \\
\text { b. Galeri liberty laundry } \\
\text { c. Tentang liberty laundry } \\
\text { d. Kontak liberty laundry } \\
\text { e. Testimoni liberty laundry }\end{array}$ & Ok \\
\hline \multirow[t]{2}{*}{ Pendaftaran } & $\begin{array}{l}\text { 1. user harus mengisi lengkap } \\
\text { data register }\end{array}$ & Ok \\
\hline & $\begin{array}{llr}\text { 2. } & \text { setelah registrasi selesai, user } \\
\text { harus } & \text { login } & \text { dengan }\end{array}$ & Ok \\
\hline
\end{tabular}




\begin{tabular}{|c|c|c|}
\hline & $\begin{array}{l}\text { memasukkan username dan } \\
\text { password }\end{array}$ & \\
\hline \multirow[t]{3}{*}{ Pemesanan } & $\begin{array}{l}\text { 1. user login dengan memasukkan } \\
\text { email dan password }\end{array}$ & Ok \\
\hline & $\begin{array}{l}\text { 2. email dan password harus di isi } \\
\text { lengkap tidak boleh kosong }\end{array}$ & Ok \\
\hline & $\begin{array}{l}\text { 3. user memilih online order, user } \\
\text { harus mengisi data pemesanan } \\
\text { dengan lengkap }\end{array}$ & Ok \\
\hline \multirow{17}{*}{$\begin{array}{l}\text { Pickup } \\
\text { delivery } \\
\text { service }\end{array}$} & $\begin{array}{l}\text { admin login dengan } \\
\text { memasukkan username dan } \\
\text { password }\end{array}$ & Ok \\
\hline & $\begin{array}{l}\text { 2. username dan password diisi } \\
\text { dengan benar, kolom username } \\
\text { dan password tidak boleh ada } \\
\text { yang kosong }\end{array}$ & Ok \\
\hline & view order service & Ok \\
\hline & 4. search order service & Ok \\
\hline & 5. delete order service & $\mathrm{Ok}$ \\
\hline & 6. view data costumer & Ok \\
\hline & search data costumer & $\mathrm{Ok}$ \\
\hline & 8. view data costumer & $\mathrm{Ok}$ \\
\hline & 9. search data costumer & Ok \\
\hline & 10. create data costumer & $\mathrm{Ok}$ \\
\hline & 11. delete data product & Ok \\
\hline & 12. view testimonial & Ok \\
\hline & 13. search testimonial & $\mathrm{Ok}$ \\
\hline & 14. update status testimonial & Ok \\
\hline & 15. view data contact & Ok \\
\hline & 16. search data contact & Ok \\
\hline & 17. delete data contact & Ok \\
\hline
\end{tabular}

\section{Maintenance}

1. Maintenance Sistem (hardware)

a. Sistem akan dilakukan cek berkala 6-12 bulan

b. Penanganan sistem dilakukan oleh $1-2$ orang

c. Backup sistem dilakukan $3-6$ bulan

2. Maintenance Sistem Aplikasi (software)

a. Jika ada perubahan dari sistem

b. Aplikasi perubahan dilakukan jika ada permintaan dari user untuk memperbaharui data.

c. Backup software dilakukan 1-2 bulan.

\section{PENUTUP}

Berdasarkan analisis masalah pada Perancangan aplikasi e-service Sistem Informasi Laundry ini dapat diambil beberapa kesimpulan, diantaranya :

a. Sistem

Sistem yang akan diajukan pada liberty laundry (UMKM) yaitu aplikasi e-service berbasis web yang bertujuan untuk :

1. Mengatasi permasalahan costumer yang memiliki keterbatasan waktu pada pengiriman ataupun pengambilan laundry.
2. E-service laundry berbasis web ini bertujuan agar costumer praktis dalam melakukan pemesanan laundry.

3. Segi bisnis membawa suatu perubahan yang baru dalam bertransaksi jasa laudry dengan menggunakan media elektronik website.

\section{DAFTAR PUSTAKA}

[1] Alexander F.K. Sibero, 2011. Kitab Suci Web Programming, Yogyakarta MediaKom.

[2] Bin Ladjamudin, Al-Bahra, 2013. Analisis dan Desain Sistem Informasi. Yogyakarta : Graha IImu.

[3] Hassan H.S., Shehab. E, Peppard J. 2011. "Recent Advances In E-Service In ThePublic Sector: State-Of-The-Art And Future Trends". Business Process Management Journal Vol. 17 No. 3.

[4] Gordon B. Davis dan Margrethe H. Olson, 1984. Management Information System, Conceptual Fundations, Structure and i i. USA : Mc Graw-Hill

[5] Kenneth E. Kendall dan Julie E. Kendal, 2006. Analisis dan Perancangan Sistem Edisi ke 5 Jilid I. Jakarta. Roger : PT. Index.

[6] Ojasalo, Jukka. 2010. E-Service Quality: A Conceptual Model. Laurea University of Applied Sciences, Finland.

[7] Parasuraman, A., Valarie A. Zeithaml, and Arvind Malhotra (2005), "E-S-QUAL A Multiple-Item Scale for Assessing Electronic Service Quality," Journal of Service Research, 7 (3), 213-33.

[8] Uysal, H.Tezcan \& Mehmet Selami Yildiz (2013), "Effect of Organizational Levels on Individual Service Quality in Health Service: A Research on Doctors". İktisat İşletme ve Finans Dergisi. 28(329), pp.21-48.

[9] Wolfinbarger, Mary, and Mary C. Gilly (2003), "Etailq: Dimensionalizing, Measuring and Predicting Etail Quality," Journal of Retailing 79 (3), 18398. Hassan H.S., Shehab. E, Peppard J. 2011. 